\title{
Avoiding traffic jams: Hitchhiking behavior as a strategy to reduce ant workers' traffic on the foraging trail
}

\author{
Isabel Neto Hastenreiter ${ }^{\mathrm{a}}$, Juliane Floriano Santos Lopes ${ }^{\mathrm{a}, \mathrm{c}}$, Roberto da Silva Camargo ${ }^{\mathrm{b}, *}$, \\ Luiz Carlos Forti ${ }^{\mathrm{b}}$
a Programa de Pós-Graduação em Ecologia, Universidade Federal de Juiz de For a, Rua José Lourenço Kelmer, s/n. Campus Universitário, Bairro São Pedro, CEP: 36036- 900, Juiz de Fora, MG, Brazil
${ }^{\mathbf{b}}$ Laboratório de Insetos Sociais-Praga, Departamento de Produção Vegetal, Setor Defesa Fitossanitária, FCA/UNESP, PO Box 237, 18603-970, Botucatu, São Paulo, Brazil
${ }^{\mathrm{c}}$ Programa de Pós-Graduação em Ciências Biológicas, Comportamento e Biologia Animal, Universidade Federal de Juiz de Fora, Rua José Lourenço Kelmer, s/n. Campus Universitário, Bairro São Pedro, CEP: 36036-900, Juiz de Fora, MG, Brazil

\section{A R T I C L E I N F O}

\section{Keywords:}

Foraging

Acromyrmex subterraneus

Traffic jam

\begin{abstract}
A B S T R A C T
During foraging, thousands of leaf-cutting ant workers travel along high traffic foraging trails which, when narrow, reduce the leaf delivery rate due to the reduction in workers' travel-speed. On the other hand, high worker traffic promotes head-on encounters which are supposed to mediate worker task allocation and so could constitute a cue which induces traffic reduction. Very small workers along trails, for example, could change their task between marking the trail chemically to hitchhiking. Since they assume the hitchhiker function even in the absence of phorid parasitoids, one can suppose that hitchhiker behavior could be a strategy mediated by head-on encounters to avoid the high density of workers. Thus, we studied how the variation of worker density on the trail influences the hitchhiker frequency, testing the hypothesis that very small workers climb on the transported leaves to reduce trail traffic. Therefore, five Acromyrmex subterraneus colonies were linked to a foraging area by trails of different width $(1.5$ or $3 \mathrm{~cm})$. We counted the number of hitchhikers and the outbound worker flow. The frequency of hitchhikers increased along narrow trails, and also due to outbound workers in both trail widths. Regardless of outbound foraging flow being comparable in both trail widths, the narrower ones had high density of workers leading to a presumed increase in head-on encounters. Head-on encounter rates cause a reduction in travel speed and, furthermore, are regulatory factors of task-allocation. Thus, high density trails lead to an increase in the rate of head-on encounters which could constitute as a stimulus to task-allocation of very small workers to the function of hitchhiker to avoid traffic jams.
\end{abstract}

\section{Significance statement}

We accessed how the variation of worker density on the trail influences the hitchhiker frequency and so test for the hypothesis that very small workers climb on the transported leaves to reduce trail traffic. We found that frequency of hitchhikers increased along narrow trails, and also due to outbound workers in both trail widths. As the outbound foraging flow being is not different in both trail widths, the narrower ones had high density of workers leading to a presumed increase in head-on encounters. Head-on encounter rates cause a reduction in travel speed and, furthermore, are regulatory factors of taskallocation. We concluded that high density trails lead to an increase in the rate of head-on encounters which could constitute as a stimulus to task-allocation of very small workers to the function of hitchhiker to avoid traffic jams

\section{Introduction}

Ant foraging is a complex process whose success depends on both the individual activity of the workers and the integrated activity of the group (Traniello, 1989; Roces and Núñez, 1993). The integration of the individual and group activity is actually a great challenge, especially because Acromyrmex species, the target organism of this research, have populous colonies with thousands of individuals moving along a trail system during foraging, generating a high-flow of traffic (Burd et al., 2002; Kost et al., 2005). Brazil has 20 species and 9 taxonomic subspecies accepted as Acromyrmex (Della-Lucia et al. 1993). During foraging, Acromyrmex workers, known as leaf-cutter ants run towards

\footnotetext{
* Corresponding author.

E-mail address: camargobotucatu@yahoo.com.br (R. da Silva Camargo).
} 
fresh leaves from different plant species, cut leaf fragments and transport them to the colony. The leaves fragments are used to feed their fungi crop, used as food source for the entire colony, specially the larvae. These activities are distributed within different size classes of workers (Forti et al., 2004).

Acromyrmex foraging trails, as well as those of other ant species, present physical trails on the surface of the soil which are actively constructed by workers (Bruce and Burd, 2012) and vary in width and length (Sales et al., 2015; Lopes et al., 2016). They can be found in places with different physical characteristics which influence ant displacement. It is known, for example, that there is an increase in worker walking speed in physically delimited litter-free trails (Sales et al., 2015). This physical delimitation leads to a higher concentration of forager workers and a consequent increase in delivery rate to the colony, either due to an increase in the worker flow (Sales et al., 2015; Bochynek et al., 2017) or to the trail pheromone concentration (Jaffé and Howse, 1979; Sumpter, 2006).

As Acromyrmex use mass recruitment as a foraging strategy, trail width is an important aspect of foraging. Narrow trails may lead to an increase in the pheromone concentration, which is done through a positive feedback mechanism (Sumpter, 2006), and also promote an increase in ant worker density transiting along the trail. When the flow increases, especially in delimited paths, there is an increase in the worker encounter rate which stimulates leaf cutting (Dussutour et al., 2007), yet causes small delays in the movement of individuals which represent a reduction of up to $20 \%$ of the displacement speed (Burd and Aranwela, 2003). The speed reduction caused by this higher rate of encounters or by the transport of large loads leads to traffic jams (Burd et al., 2002; Farji-Brener et al., 2011).

Workers are expected to adjust their behavior in a way that minimizes the effect of the high density of individuals along the trail, thus avoiding traffic jams and consequent delays in leaf delivery. One strategy observed is the reduction of fragment sizes cut when in high traffic of individuals (Farji-Brener et al., 2011). The same has already been registered when the trail width is manipulated (Dussutour et al., 2009a,b).

In ants, encounter rates provide information about how many individuals are engaged in a particular activity since they are dependent on collective characteristics, such as group size or density (Gordon and Mehdiabadi, 1999). As a result, when encounter rates vary there is an adjustment in the number of individuals performing different tasks, in a self-organizing process, with forager workers responding to these localized and simple signals (Gordon and Mehdiabadi, 1999). However not all workers respond at the same way to encounter rates.

Along the foraging trail, very small workers are primarily responsible for pheromone trail marking (Evison et al., 2008). When the flow of workers is high enough to effectively perform the chemical marking, any excess workers already out of the nest could then be allocated to another task. Indeed, very small workers have already been observed displaying hitchhiking behavior (Stradling, 1978) in which they climb on the leaf fragments transported by their nestmates.

It is known that very small workers assume the hitchhiking behavior when they detect that foragers are under attack by phorids (Feener and Moss, 1990; Bragança et al., 1998). However, the same behavior is also observed in the absence of phorids (Hastenreiter et al., 2016), which indicates that other stimuli could induce hitchhiking behavior. Since higher worker density increases the encounter rate, and this increased rate is related to task allocation, it is reasonable to assume that very small workers could change to the task of hitchhiking due to the rise of worker density along the trail. Therefore, this study evaluated whether the worker density variation in trails influences the hitchhiking frequency.

\section{Material and methods}

The experiment was carried out at the Laboratory of Myrmecology at the Federal University of Juiz de Fora, using five colonies of Acromyrmex subterraneus with similar fungus volume (2.5 liters). The colonies were kept under a controlled temperature and relative humidity ( $\mathrm{T}=22^{\circ}$ to $25^{\circ} \mathrm{C}$, $\mathrm{RH}=$ approximately $80 \%$ ) and daily kept with fresh leaves of Acalypha wilkesiana and Delonyx regia. For the experiment, the colonies were leaf-deprived for $24 \mathrm{~h}$ prior to the test series.

Each colony was connected to the foraging arena by a 70-cm-long glass bridge. We used two bridge widths, which constituted our treatments: (i) wide trail $-3-\mathrm{cm}$ wide; (ii) narrow trail $-1.5-\mathrm{cm}$ wide. At the end of the trail in the foraging arena, we supplied 100 discs of $A$. wilkesiana $\left(52 \mathrm{~mm}^{2}\right)$ cut with a manual metal punch from fresh leaves harvested prior to the experiment.

At the center of the glass bridge, we established a point for recording the frequency of hitchhikers that were on the leaves as well as the flow of workers leaving the nest towards the foraging arena. We counted the flow during one minute with intervals of five minutes. As a result, it was possible to calculate the average flow for the entire foraging process. The assay was ended when all the leaf discs were transported.

We submitted each of the five colonies to each treatment at least five times. Where no hitchhiker was observed, the assay has been excluded, because in this case the outbound worker flow was lower than on the other assays. We performed a total of 34 experimental assays $(17 /$ treatment).

Data were submitted to the Bartlett and Shapiro-Wilk tests for homoscedasticity and normality, respectively. If homoscedasticity and/ or normality were not verified, data was $\log 10$ transformed. Afterwards, data were submitted to GLM to evaluate if the hitchhiker frequency and the flow of workers leaving the nest (response variables) varied according to the trail width (explicative variable) and colony as random variable, to control for data pairing. A linear regression was conducted to verify if hitchhiker frequency was related to the flow of workers that left the nest. All analyzes were performed at $5 \%$ level of significance in R software (R Development Core Team, 2017 - version 3.4.3).

\section{Results}

The frequency of hitchhikers varied according to the trail width ( $\mathrm{F}$ $(1,29)=6.32, \mathrm{p}=0.017$ ) being greater in the narrow trail (Fig. $1 \mathrm{~A})$. On the other hand, the flow of workers leaving the nest did not $(\mathrm{F}(1$, $29)=0.01, p=0.89$ ) (Fig. 1B), meaning that if there is the same number of individuals on the narrow trail, it presents a higher worker density in comparison to the wide one.

Also, we verified a positive relationship between hitchhiker frequency and the number of workers leaving the nest $(\mathrm{F}(1,29)=12.17$, $\mathrm{p}=0.001, \mathrm{R}^{2}=0.25$ ) (Fig. 2).

\section{Discussion}

The higher hitchhiker frequency on narrow trails indicates that the hitchhiking task may constitute a behavioral strategy in conditions of high worker density on the trail. On the other hand, the reduction in trail width did not influence the flow of workers leaving the nest; the average number of workers in the wide and narrow trails was similar and in both cases had a increasing effect on the hitchhiker frequency. Therefore, since the worker flow did not vary according to the trail width yet did influence the hitchhiker frequency, we can assume that an increase in worker density due to narrowing the trail width stimulated the hitchhiking behavior.

Physical trails are like corridors linking the colony to the food patches and through which scouts, foragers and very small ants (Shepherd, 1982; Sumpter, 2006; Evison et al., 2008) transit and deposit pheromones. In narrower trails, it is expected that pheromone deposits will be more localized as the superficial area is smaller. Since 

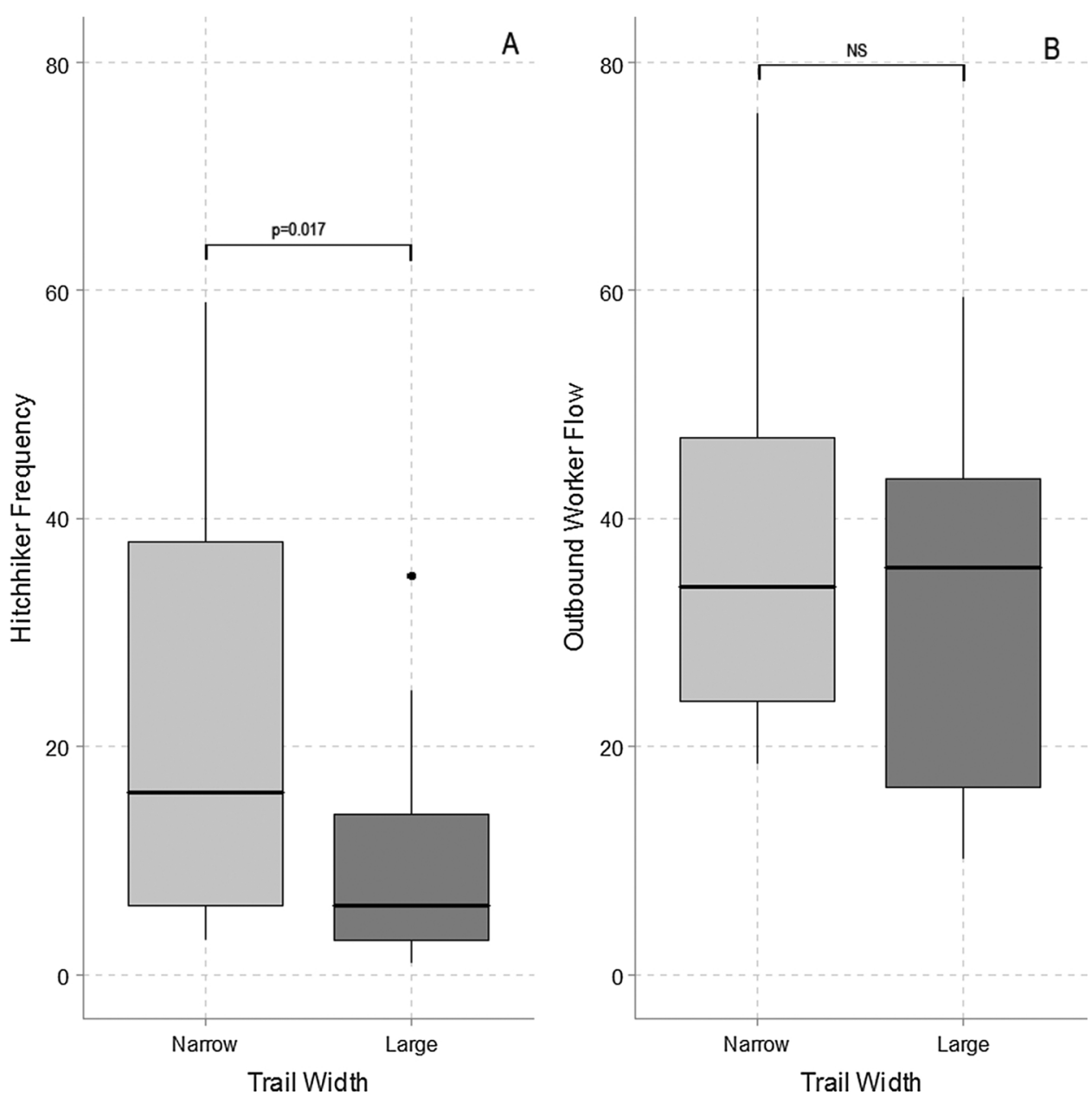

Fig. 1. Median and range of hitchhiker frequency (A) and outbound worker flow (B) in A. subterraneus, according the trail width.

the worker flow was similar in both narrow and wide trails, we can suppose that trail pheromone is more accumulated on narrow trails, what increases the probability of phorids flying over the trail under natural conditions. It is known that phorids are attracted by the most diverse volatile compounds, including trail and alarm pheromones (reviewed by Mathis and Phillpott, 2012). Since the hitchhikers are related to the forager worker defense against parasitoid phorids attack, we can assume that the very small ants could be stimulated by the pheromone accumulation to assume the task of hitchhikers.

Another effect of narrowing of the trail width and consequent increase in the density of individuals is that the encounter rate among workers also increases (Burd and Aranwela, 2003). Such nest-mate encounters are recognized as important regulators of task allocation (Gordon, 2002; Gordon and Mehdiabadi, 1999). Therefore, we believe that on narrow trails, hitchhiking behavior may have been more often stimulated due to the increased encounter rate caused by reduced trail width. Indeed, during foraging, the level of stimulus may result in a change in task allocation in which workers who are not engaged in a given function begin to do so (Waddington and Hughes, 2010). The main function of very small workers is chemical trail marking (Evison et al., 2008). However, this task is also carried out by medium and large workers (foragers) when the flow is already established along the trail (Sumpter, 2006). In this case, very small ants along the trail would be available to carry out other foraging-related functions. By assuming the hitchhiker role, very small workers would perform the tasks related to this behavior and still save energy to return to the nest (Feener and Moss, 1990), reflecting on the colony-level benefits of increased traffic flow and energy savings.
One of the explanatory models of task allocation dynamics states that the individual decision for a worker to engage in a task is based on environmental and social stimuli (Pacala et al., 1996; Gordon, 2003). In this study, we suggest that especially the local stimuli may have caused the hitchhiking frequency increase due to narrow trails amplifying nestmate encounter rates.

It has been documented that in narrow trails the workers are able to avoid traffic jams by behavioral mechanisms. When an alternative route is made available, a portion of the workers goes to the alternative trail after meeting with a nestmate who traveled in the opposite direction, dividing the foraging flow (Dussutour et al., 2004). Additionally, the flow can be organized temporally in alternate blocks of workers leaving and returning to the nest (Dussutour et al., 2005). These behavioral strategies are seen as alternatives to reduce the encounter rate among workers and to avoid subsequent delays (Dussutour et al., 2005). Other strategies related to traffic jams is the reduction in transported leaf fragment size, preventing the truck-effect (Farji-Brener et al., 2011) and the spatial organization of worker flow in which very small workers travel along the outer side of the trail while loaded workers travel along the middle (Brugger, 2015).

The stimulus for hitchhiking behavior by different agents is already known in the literature (phorids: Feener and Moss, 1990, vibration: Roces and Hölldobler, 1995). In this study, we add the high density of individuals along the trail to these agents, which constitutes a great potential for traffic jams. Such jams generate costs ranging from leaf delivery rate decreasing to a reduction of up to $20 \%$ in forager walking speed (Burd and Aranwela, 2003). Also, due to traffic jams, workers remain a longer period outside the nest, increasing the risks of 


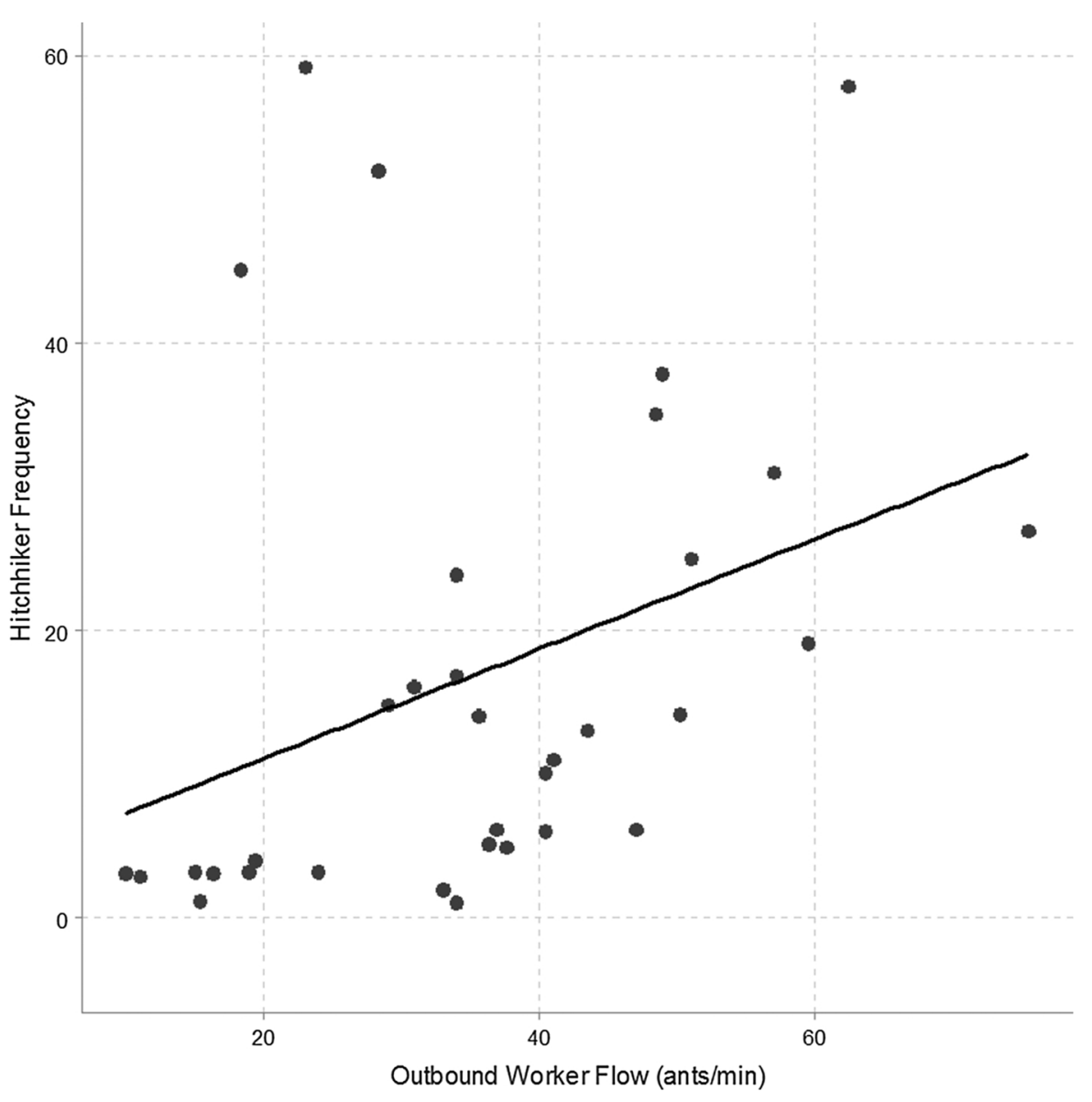

Fig. 2. Correlation of hitchhiker frequency with outbound worker flow in A. subterraneus.

desiccation, competition (de Biseau et al., 1997) and attack by parasitoids (Feener and Moss, 1990). In order to avoid traffic jams and consequent delays in returning to the nest, becoming a hitchhiker on narrow trails could be an excellent strategy. By hitchhiking there are two individuals occupying a smaller space when compared to these same individuals walking along the trail. In this study, we indicated that the hitchhiking behavior represents a new strategy to avoid traffic jams on the trail.

\section{Funding}

LCF was the recipient of a grant from Conselho Nacional de Desenvolvimento Cientifico e Tecnológico (Grant 301718/2013-0).

\section{Conflict of interest}

The authors declare no conflict of interest.

\section{Ethical approval}

All applicable international, national and institutional guidelines for the care and use of animals were followed. Ants were collected and handled with the permission of the IBAMA (licences 16284-1).

\section{Informed consent}

This article does not contain any studies with human participants or animals performed by any of the authors.

\section{References}

Bochynek, T., Meyer, B., Burd, M., 2017. Energetics of trail clearing in the leaf-cutter ant Atta. Behav. Ecol. Sociobiol. 71, 14.

Bragança, M.A.L., Tonhasca, J.R.A., Della Lucia, T.M.C., 1998. Reduction in the foraging activity of the leaf-cutting ant Atta sexdens caused by the phorid Neodohrniphora sp. Entomol. Exp. Appl. 89, 305-311.

Bruce, A., Burd, M.C., 2012. Allometric scaling of foraging rate with trail dimensions in leaf-cutting ants. Proc. R. Soc. B: Biol. Sci. 279, 2442-2447.

Brugger, M.S., 2015. Na trilha com as escoteiras: como as operárias sabem o caminho a seguir. PhD thesis. Unesp, Botucatu, São Paulo, Brasil.

Burd, M., Aranwela, N., 2003. Head-on encounter rates and walking speed of foragers in leaf-cutting ant traffic. Insectes Soc. 50, 3-8. https://doi.org/10.1007/ s000400300001.

Burd, M., Archer, D., Aranwela, N., Tradling, D., 2002. Traffic dynamics of the leaf-cutting ant, Atta cephalotes. Am. Nat. 159, 283-293.

de Biseau, J.C., Quinet, Y., Deffernez, L., Pasteels, J.M., 1997. Explosive food recruitment as a competitive strategy in the ant Myrmica sabuleti (Hymenoptera, Formicidae). Insectes Soc. 44, 59-73. https://doi.org/10.1007/s000400050023.

Dussutour, A., Fourcassié, V., Helbing, D., Deneubourg, J.L., 2004. Optimal traffic organization in ants under crowded conditions. Nature 428, 70-73.

Dussutour, A., Deneubourg, J.L., Fourcassié, V., 2005. Temporal organization of bi-directional traffic in the ant Lasius niger (L.). J. Exp. Biol. 208, 2903-2912.

Dussutour, A., Beshers, S., Deneubourg, J.L., Fourcassié, V., 2007. Crowding increases foraging efficiency in the leafcutting ant Atta colombica. Insectes Soc. 54, 158-165. https://doi.org/10.1007/s00040-007-0926-9.

Dussutour, A., Deneubourg, J.L., Beshers, S., Fourcassié, V., 2009a. Individual and collective problem-solving in a foraging context in the leaf-cutting ant Atta colombica. Anim. Cogn. 12, 21-30.

Dussutour, A., Beshers, S., Deneubourg, J.L., Fourcassié, V., 2009b. Priority rules govern the organization of traffic on foraging trails under crowding conditions in the leafcutting ant Atta colombica. J. Exp. Biol. 212, 499-505.

Evison, S.E.F., Hart, A.G., Jackson, D.E., 2008. Minor workers have a major role in the maintenance of leafcutter ant pheromone trails. Anim. Behav. 75, 963-969.

Farji-Brener, A.G., Chinchilla, F.A., Rifkin, S., Cuervo, A.M.S., Triana, E., Quiroga, V., Giraldo, P., 2011. The 'truck-driver' effect in leaf-cutting ants: how individual load influences the walking speed of nest-mates. Physiol. Entomol. 36, 128-134. https:// doi.org/10.1111/j.1365-3032.2010.00771.x.

Feener Jr., D.H., Moss, K.A.G., 1990. Defense against parasites by hitchhikers in leaf- 
cutting ants: a quantitative assessment. Behav. Ecol. Sociobiol. 26, 17-29.

Forti, L.C., Camargo, R.S., Matos, C.A.O., Andrade, A.P.P., Lopes, J.F.S., 2004. Aloetismo em Acromyrmex subterraneus brunneus Forel (Hymenoptera, Formicidae), durante o forrageamento, cultivo do jardim de fungo e devolução dos materiais forrageados. Rev. Bras. Entomol. 48 (1), 59-63.

Gordon, D., 2002. The regulation of foraging activity in red harvester colonies. Am. Nat. 159, 509-518.

Gordon, D.M., 2003. The Organization of Work in Social Insect Colonies, vol. 8 Wiley Periodicals, Inc. No. 1.

Gordon, D.M., Mehdiabadi, N., 1999. Encounter rate and task allocation in harvester ants. Behav. Ecol. Sociobiol. 45, 370-377.

Hastenreiter, I.N., de Sales, T.A., Ribeiro, L.F., et al., 2016. A convenient trip: an analysis of the impact of hitchhiker ants on forager transport rates. J. Insect Behav. 29, 37. https://doi.org/10.1007/s10905-015-9540-2.

Jaffé, K., Howse, P.E., 1979. The mass recruitment system of the leaf-cutting ant, Atta cephalotes (L). Anim. Behav. 27, 930-939. https://doi.org/10.1016/0003-3472(79) 90031-9.

Kost, C., Gama de Oliveira, G., Knoch, T., Wirth, R., 2005. Spatio-temporal permanence and plasticity of foraging trails in young and mature leaf-cutting ant colonies (Atta spp.). J. Trop. Ecol. 21, 677-688.

Lopes, J.F.S., Brugger, M.S., Menezes, R.B., Camargo, R.S., Forti, L.C., Fourcassié, V., 2016. ) Spatio temporal dynamics of foraging networks in the grass-cutting ant Atta bisphaerica Forel, 1908 (Formicidae, Attini). PLoS One 11, e0146613. https://doi. org/10.1371/journal.pone.0146613.

Mathis, K.A., Phillpott, S.M., 2012. Current understanding of future prospects of host selection, acceptance, discrimination, and regulation of phorid fly parasitoids that attack ants. Psyché, 8954249 p.

Pacala, S.W., Gordon, D.M., Godfray, H.C.J., 1996. Effects of social group size on information transfer and task allocation. Evol. Ecol. 10, 127-165.

R Development Core Team, 2017. R: a Language and Environment for Statistical Computing. URL. R Foundation for Statistical Computing, Vienna, Austria Acesssed 03 July 2018. http://www.R-project.org.

Roces, F., Hölldobler, B., 1995. Vibrational communication between hitchhikers and foragers in leaf-cutting ants (Atta cephalotes). Behav. Ecol. Sociobiol. 37, 297-302.

Roces, F., Núñez, J.A., 1993. Information about food quality influences load-size selection in recruited leaf-cutting ants. Anim. Behav. 45, 135-143.

Sales, T.A., Hastenreiter, I.N., Almeida, N.G., Lopes, J.F.S., 2015. Fast food delivery: is there a way for foraging success in leaf-cutting ants? Sociobiology 62, 513-518 https://doi.org/10.13102/sociobiology.v62i4.807.

Shepherd, J.D., 1982. Trunk trails and the searching strategy of a leaf-cutter ant, Atta colombica. Behav. Ecol. Sociobiol. 11, 77-84. https://doi.org/10.1007/BF00300095.

Stradling, D.J., 1978. The influence of size on foraging in the ant, Atta cephalotes, and the effect of some plant defence mechanisms. J. Anim. Ecol. 47, 173-188.

Sumpter, D.J.T., 2006. The principles of collective animal behavior. Philos. Trans. R. Soc Lond. B Biol. Sci. 361, 5-22. https://doi.org/10.1098/rstb.2005.1733.

Traniello, J.F.A., 1989. Foraging strategies of ants. Annu. Rev. Entomol. 34, 191-210.

Waddington, S.J., Hughes, W.O.H., 2010. Waste management in the leaf-cutting ant Acromyrmex echinatior: the role of worker size, age and plasticity. Behav. Ecol. Sociobiol. 64, 1219-1228. 